\title{
Miniaturized Most Probable Number for the \\ Enumeration of Salmonella sp in Artificially \\ Contaminated Chicken Meat
}

ISSN 1516-635X Jan - Mar 2014 / v.16 / n.1 / 45-48

Author(s)
Colla FL',II
Mion L',II
Parizotto L',IV
Rodrigues LB'
Pilotto F'
Dickel EL'
Nascimento VP dov
Santos LR dos'
। Curso de Medicina Veterinária da Faculda-
de de Agronomia e Medicina Veterinária da
Universidade de Passo Fundo (UPF).
" Bolsista Pibic-CNPq.
III Bolsista Probic FAPERGS.
Iv Bolsista Pibic UPF.
v Faculdade de Medicina Veterinária da Uni-
versidade Federal do Rio Grande do Sul
(UFRGS).

\section{Mail Adress}

Corresponding author e-mail address Luciana Ruschel dos Santos.

Curso de Medicina Veterinária da UPF. Campus I, BR 285, Bairro São José. Caixa Postal 611.Passo Fundo, RS. CEP 99052900.

E-mail: luruschel@upf.br

\section{-Keywords}

Chicken meat, most probable number, Salmonella.

\begin{abstract}
Salmonella is traditionally identified by conventional microbiological tests, but the enumeration of this bacterium is not used on a routine basis. Methods such as the most probable number (MPN), which utilize an array of multiple tubes, are time-consuming and expensive, whereas miniaturized most probable number (mMPN) methods, which use microplates, can be adapted for the enumeration of bacteria, saving up time and materials. The aim of the present paper is to assess two mMPN methods for the enumeration of Salmonella sp in artificiallycontaminated chicken meat samples. Microplates containing 24 wells (method A) and 96 wells (method B), both with peptone water as preenrichment medium and modified semi-solid Rappaport-Vassiliadis (MSRV) as selective enrichment medium, were used. The meat matrix consisted of $25 \mathrm{~g}$ of autoclaved ground chicken breast contaminated with dilutions of up to $10^{6}$ of Salmonella Typhimurium (ST) and Escherichia coli (EC). In method A, the dilution $10^{-5}$ of Salmonella Typhimurium corresponded to $>57 \mathrm{MPN} / \mathrm{mL}$ and the dilution $10^{-6}$ was equal to $30 \mathrm{MPN} / \mathrm{mL}$. There was a correlation between the counts used for the artificial contamination of the samples and those recovered by mMPN, indicating that the method A was sensitive for the enumeration of different levels of contamination of the meat matrix. In method $B$, there was no correlation between the inoculated dilutions and the mMPN results.
\end{abstract}

\section{INTRODUCTION}

Bacteria of the genus Salmonella play a major role in poultry farming. Avian-adapted serovars cause gastroenteritis, septicemia and eventually impair productivity, while human-adapted typhoidal serovars cause gastroenteritis and are major barriers for the exports of poultry products. The identification of Salmonella in products of animal origin by qualitative methods (conventional microbiological tests) is widely acknowledged, but the enumeration of this microorganism is not used on a routine basis (Borowsky et al., 2005). Enumeration at the poultry farm level up to processing is crucial to estimate the extent of contamination of meat cuts and carcasses and to assess the efficacy of Good Manufacturing Practices (GMP) and Hazard Analysis and Critical Control Points (HACCP) used for the control of pathogens (Borsoi et al., 2010).

Enumeration methods such as the most probable number (MPN) allow estimating bacterial population based on statistical probabilities and can be combined with Salmonella identification methods (Cavada et al., 2010). However, as the MPN method uses multiple tubes, it is not very practical for multiples analysis, especially when several samples are simultaneously analyzed in Salmonella control programs. 
Miniaturized most probable number (mMPN) methods, which use microplates, can be adapted for the enumeration of microorganisms, saving time and materials (Oscar, 2004; Skovgaard, 2005). Fravalo et al. (2003) proposed an mMPN method using the modified semi-solid Rapapport Vassiliadis (MSRV) medium for the selection of motile Salmonella strains and later growth in chromogenic media. Pavic et al. (2009) validated an mMPN method based on ISO 6579:2002 using MSRV and found no significant differences between traditional MPN (tNMP) and mNMP. The methods developed by Fravalo et al. (2003) and Pavic et al. (2009) employed mNMP for enumeration and MSRV as enrichment medium in pig slurry and poultry meat matrices, respectively. Nevertheless, there are no studies comparing these methods in chicken meat. Therefore, the aim of this paper is to assess two mNMP methods for the enumeration of Salmonella $\mathrm{sp}$ in artificially-contaminated chicken meat samples.

\section{MATERIAL AND METHODS}

The method adapted from Fravalo et al. (2003), referred to as method $A$ (24-well microplates), and the method adapted from Pavic et al. (2009), referred to as method B (96-well microplates), were used. The meat matrix consisted of $25 \mathrm{~g}$ of autoclaved ground chicken breast inoculated with positive(Salmonella Typhimurium ATCC 14028, ST) and negative (Escherichia coli ATCC 25922, EC) controls. In the stationary phase, the controls were inoculated in $9 \mathrm{~mL}$ of peptone water at $1 \%$ (PW $1 \%$ )for $24 \mathrm{~h}$ at $37^{\circ} \mathrm{C}$, with dilution up to $10^{-}$ 6. The conventional qualitative microbiological analysis (ISO 6579: 2002) was carried out concomitantly with methods $A$ and $B$.

\section{Method A}

(adapted from Fravalo et al., 2003)

An aliquot of $225 \mathrm{~mL}$ of PW 1\% was added to the meat matrix and $1 \mathrm{~mL}$ of $10^{-5}$ and $10^{-6}$ dilutions of ST and EC controls was used for contamination. A volume of $17.5 \mathrm{~mL}$ was transferred to a sterile tube, of which $10 \mathrm{~mL}$ were used for the conventional microbiological analysisand $2.5 \mathrm{~mL}$ were transferred to the first three wells in the first row of the 24-well microplates. In each well, $0.5 \mathrm{~mL}$ were transferred to $2 \mathrm{~mL}$ of buffered PW $1 \%$, previously poured into the subsequent rows, with three successive dilutions(Figure 1). The samples were pre-enriched for $16-20 \mathrm{~h}$ at $37^{\circ} \mathrm{C}$ and kept in an

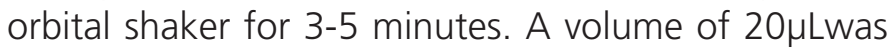
transferred from each well to the corresponding well in a microplate containing $2 \mathrm{~mL}$ of MSRV (WorcmanBarninka et al., 2001), and incubated for24-48 h at $42^{\circ} \mathrm{C}$. Aliquots from wells in which there was color change in the MSRV were streaked onto chromogenic agar $\left(\right.$ Laborclin $\left.^{\circledR}\right)$, XLD and brilliant green agar, and colonies suggesting the presence of Salmonella were submitted to biochemical tests in TSI (Triple Sugar Iron), LIA(Lysine Iron Agar), SIM (Sulfide-Indole-Motility), and urea broth, and to a serological test with Salmonella polyvalent $\mathrm{O}$ antiserum.

Non-decimal serial dilutions were calculated by the simplified MPN formula (Thomas, 1942), that is, MPN / $g$ or $\mathrm{mL}=\mathrm{P} / \sqrt{ } \mathrm{NT}$, where $\mathrm{P}$ is the number of positive tubes, $\mathrm{N}$ is the sum of the amount of sample inoculated into all negative tubes and $T$ is the sum of the amount of sample inoculated into all tubes. The application of this formula was compared with the results obtained by the MPN Calculator (Curiale, 2012), using the combination of positive wells in series of 3, with inoculated amounts of 1,0.5,0.1, and 0.02 $\mathrm{mL}$ in four dilutions.

\section{Method B}

(adapted from Pavic et al., 2009)

For inoculation in the miniaturized system of 96well microplates, $900 \mathrm{uL}$ of buffered PW $0.1 \%$ were added to each well and $100 \mathrm{uL}$ were transferred from each contaminated matrix to the first three wells in the microplate. Serial dilutions were obtained and the sample was homogenized with aspirations repeated 10 times up to dilution $10^{-8}$. The microplates were covered in plastic film and incubated for $24 \mathrm{~h}$ at $37^{\circ} \mathrm{C}$. The total volume of each well $( \pm 1 \mathrm{~mL})$ was transferred to a new microplate containing $500 \mathrm{uL}$ of MSRV and incubated for $24-48 \mathrm{~h}$ at $42^{\circ} \mathrm{C}$ (Figure 2). Aliquots of wells in which there was color change in the MSRV were streaked onto chromogenic agar (Laborclin $\left.{ }^{\circledR}\right)$, XLD and brilliant green agar. The plates were incubated for $24 \mathrm{~h}$ at $37^{\circ} \mathrm{C}$ and the colonies suggesting the presence of Salmonella were identified as in method A.

\section{RESULTS AND DISCUSSION}

In method A (adapted from Fravallo et al., 2003), the dilution $10^{-5}$ of Salmonella Typhimurium corresponded to $>57 \mathrm{MPN} / \mathrm{mL}$ and the dilution $10^{-6}$ was equal to 30 $\mathrm{MPN} / \mathrm{mL}$. There was a correlation between the counts used for the artificial contamination of the samples and those recovered by mMPN, indicating that the method was sensitive for the identification of different levels 
of contamination of the meat matrix. Fravallo et al. (2003) tested fecal samples and environmental swabs obtained from a pig slaughter house and from wattles of turkeys and found similar MPN results to those of the inoculum. Only one sample with an inoculum of0.8 / g of Salmonella Typhimurium was not detected by mMPNin the MSRV medium, which, however, was detected by the conventional microbiological analysis. The replacement of the Rappaport-Vassiliadis broth with the MSRV medium allows for efficient, quick and sensitive detection of motile Salmonella spp. (Vassiliadis et al. 1978), as demonstrated by De Smedt et al.(1986), who showed that MSRV allowed detecting $100 \%$ of Salmonella spp. at concentrations of $60 \mathrm{CFU} / \mathrm{mL}$.

In method B (adapted from Pavic et al., 2009), it was not possible to establish a correlation between the inoculated dilutions and mMPN results. These results are at odds with those obtained by Pavic et al. (2009), who were able to retrieve Salmonella regardless of the type of matrix used. Those authors reported a $92 \%$ correlation and less than \pm 1 log of difference when using S. Typhimurium, Infantis, Montevideo, Muenster and Salmonella sub sp II 1,4,12,27:b: [e,n,x] (Sofia) in naturally- and artificially-contaminated samples (carcasses, scalding tank water, feces, ceca and feed) of poultry products. When developing the technique, the authors found out that, independently of the type of matrix or of the level of coexisting flora, mMPN was able to detect and enumerate Salmonella both in naturally- and artificially-contaminated samples.

Skjerve \& Olsvik (1991) state that the type of matrix can affect the sensitivity and specificity of the isolation protocol, where the selected matrices represent critical poultry facilities (USDA-FSIS, 2008), ranging from poorly humid and highly humid samples (carcasses and scalding tank water, respectively) to highly competitive environments (ceca and feces).

On the other hand, the method adapted from Fravalo et al. (2003) proved to be applicable and practical for the enumeration of Salmonella, in line with Robinault et al. (2005) and Fablet et al. (2006). The authors assert that the method is suitable for the enumeration of Salmonella in pig slurry, allowing for the count of bacteria even at low concentrations, proving to be a safe, easy and low-cost method, as miniaturization expedites the analyses and reduces the volume of reagents, enabling the simultaneous analysis of several samples.

The adequacy of the mMPN method adapted from Fravalo et al. (2003) can be inferred from the study of Cavada et al. (2010), who compared the conventional
MPN methods developed by Escartín et al. (2000), Koivunen et al. (2003) and Sanguinetti et al. (2005) for enumeration of Salmonella in pig slurry and found that only the technique proposed by Escartín et al. (2000) was able to enumerate Salmonella at similar counts as those obtained by artificial contamination, whereas in the other methods, the inoculum was way beyond detectable levels. However, the method proposed by Escartín et al. (2000) is costly compared with miniaturized techniques and does not allow for the simultaneous analysis of several samples due to the large number of tubes and culture media required. Pavic et al. (2009), after assessing the costs and feasibility of mMPN, showed that this method required $64 \%$ fewer culture media and that it was $56 \%$ less laborious than the traditional MPN (tMPN).

The technique described by Fravallo et al. (2003) and used in the present paper allowed proper enumeration of Salmonella for hazard analysis. The use of quantitative methods for the control of contamination levels and microbiological risks observed in the production chain is essential for determination of critical points of contamination by Salmonella at the farm level up to the storage of chicken parts and carcasses under refrigeration or freezing. The enumeration of Salmonella throughout the slaughtering process allows the review of quality control measures at the company level and the adoption of new strategies, as it indicates the critical points of contamination and multiplication of this pathogen during the slaughtering process.

In the method adapted from Fravallo et al. (2003), the dilution $10^{-5}$ of Salmonella Typhimurium corresponded to $>57 \mathrm{MPN} / \mathrm{mL}$ and the dilution $10^{-6}$ was equal to 30 $\mathrm{MPN} / \mathrm{mL}$. There was a correlation between the counts used for the artificial contamination of the samples and those recovered by mMPN, indicating that the method is sensitive for the enumeration of different levels of contamination of the meat matrix. In the method adapted from Pavic et al. (2009), no correlation could be established between the inoculated dilutions and mMPN results.

\section{REFERENCES}

Borowsky LM. Comparação de dois métodos de quantificação de Salmonella sp. em embutidos suínos [dissertation]. Porto Alegre (RS): Universidade Federal do Rio Grande do Sul; 2005.

Borsoi A, MoraesHLS, Salle CTP, Nascimento VP. Número mais provável de Salmonella isoladas de carcaças de frango resfriadas. Ciência Rural 2010;40:2338-2342. 
Cavada CA, Cardoso FM, Schimidt V. Comparison of three methods for Salmonella sp. quantification in wast water. Acta Scientiae Veterinariae 2010;38:17-23.

Curiale M. MPN calculator, Build. [cited Jan 2012]. Available from: http:// members.ync.net/mcuriale/mpn/index.html.

De Smedt JM, Bolderdijk R, Rappold H. Lautenschlaeger D. Rapid Salmonella detection in foods by motility enrichment on a modified semi-solid Rappaport- Vassilisdis medium. Journal of Food Protection 1986:49:510-514

Escartín EF, Lozano JS, Garcia OR. Quantitative survial of native Salmonella serovars during storage of frozen raw pork. International Journal of Food Microbiology 2000;54:19-25.

Fablet $\mathrm{CH}$, Robinault C, Jolly JP, Collet M, Chemaly M, Labbé A, Madec $\mathrm{F}$, Fravalo $\mathrm{PH}$. Salmonella enterica level in French pig farms effluents: experimental and field data. Livestock Science 2006;102:216-225.

Fravalo PH, Hascoet Y, Le Fellic M, Quegumer S, Petton J, Salvat G. Convenient method for rapid and quantitative assessment of Salmonella enteric contamination: the mini-MSRV MPN technique. Journal of Rapid Methods and Automation in Microbiology 2003;11:81- 88.

Koivunen J, Siitonen A, Heinonen-Tanski H. Elimination of enterec bacteria in biological-chemical wastewater treatment and tertiary filtration units. Water Research 2003;37:690- 698.

Oscar T. Simulation model enumeration of Salmonella. Journal Food Protetction 2004:67:1201-1208.

Pavic A, Groves PJ, Bailey G, Cox JMA validated miniaturized MPN method, based on ISO 6579:2002 for the enumeration of Salmonella from poultry matrices. Journal of Applied Microbiology 2010;109:25-34
Robinault C, Chemaly M, Fablet CH, Labbé A, Jolly JP, Madec F, Fravalo $\mathrm{PH}$. Influence and interaction of different parameters on the survival of two strains of Salmonella enterica in pig slurry. The Netherlands: International Society for Animal Hygiene; 2005 [retrieved Jan 2012]. Available from: http://www.isah-soc.org/documents/2005/sections/73_ vol_2.pdf.

Sanguinetti GS, Tortul C, Garcia MC, Ferrer V, Montgero A, Strauss M. Investigating helminth eggs and Salmonella sp. in stabilization ponds treating septage. Water Science \& Technology 2005; 51:239-247.

Silva N, Junqueira VCA, Silveira NFA. Manual de métodos de análise microbiológica de alimentos. $3^{a}$ ed. São Paulo: Livraria Varela; 2007.

Skjerve E, Olsvik O. Immunomagnetic separation of Salmonella from foods. International Journal of Food Microbiology 1991;14:11-18.

Skovgaard N. Current topics in food microbiology. International Journal Food Microbiology 2005; 99:107-111.

Thomas HA. Bacterial densities from fermentation tube tests. Journal of the American Water Association 1942;34:572-576.

United States Department of Agriculture -USDA, Food Safety Inspection Serivce. Compliance guideline for controlling salmonella and campylobacter in poultry. 2nd ed. 2008 [cited 2008 Set]. Available from: http://www.fsis.usda.gov.

Vassiliadis P, Trichopoulos D, Kalandidi A, Xirouchaki E. Isolation of salmonellae from sewage with a new procedure of enrichment. Journal of Applied Bacteriology 1978;44:233-239.

Worcman-Barninka D, Destro MT, Fernandes SA, Landgraf M. Evaluation of motility enrichment on modified semi-solid Rappaport-Vassiladis medium (MSRV) for the detection of Salmonella in foods. International Journal of Food Protection 2001;64:387-393. 